\title{
Comparison of the Effects of Trinitroglycerin Infusion and Labetalol in the Management of Acute Arterial Hypertension in Intracerebral Hemorrhage Patients Admitted to an Intensive Care Unit
}

\author{
Arash Mosalrezaei', Mohammad Amin Valizade Hasanloei2,", Azra Kahoorian ${ }^{3}$ \\ ${ }^{1}$ Assistant Professor, Department of Neurology, School of Medicine, Urmia University of Medical Sciences, Urmia, Iran \\ ${ }^{2}$ Associate Professor, Department of Anesthesiology, School of Medicine, Urmia University of Medical Sciences, Urmia, Iran \\ ${ }^{3}$ General Practitioner, Uremia University of Medical Sciences, Urmia, Iran \\ * Corresponding Author: Mohammad Amin Valizade Hasanloei, Department of Anesthesiology, School of Medicine, Urmia \\ University of Medical Sciences, Urmia, Iran.Email: aminvalizade@yahoo.com
}

\begin{tabular}{|c|c|}
\hline & Abstract \\
\hline $\begin{array}{l}\text { Received: } 26.11 .2017 \\
\text { Accepted: } 16.04 .2018\end{array}$ & \multirow{4}{*}{$\begin{array}{l}\text { Background and Objective: Intracerebral hemorrhage (ICH) is } \\
\text { caused by bleeding within brain parenchyma and the formation of regional } \\
\text { hematoma. In this study, we compared the effects of trinitroglycerin (TNG) } \\
\text { and labetalol in controlling arterial hypertension in patients with ICH } \\
\text { admitted to the intensive care unit (ICU) of Imam Hospital in Urmia city, } \\
\text { Iran. } \\
\text { Materials and Methods: We selected } 54 \text { patients, } 20 \text { of whom were treated } \\
\text { with labetalol (preferred treatment) and } 34 \text { received TNG serum infusion. } \\
\text { Demographic information, disease severity (using ICH score, Acute } \\
\text { Physiologic Assessment and Chronic Health Evaluation II [APACHEII] } \\
\text { score, and Glasgow Coma Scale [GCS]), and the initial size of the hematoma } \\
\text { (by computed tomography scan imaging) were recorded. Systolic and } \\
\text { diastolic blood pressure were measured every one hour for } 24 \text { hours. The } \\
\text { data were analyzed using the appropriate statistical tests in SPSS, version } 20 . \\
\text { Results: The mean GCS scores in the labetalol and TNG groups were } \\
10.45 \pm 4.11 \text { and } 10.17 \pm 4.44 \text {, respectively ( } \mathrm{P}=0.82 \text { ). At the time of detection, } \\
\text { the mean amount of hematoma in the labetalol group was } 65.15 \pm 24.2 \text { cc, and } \\
\text { in TNG group, it was } 63.16 \pm 28.1 \text { cc ( } \mathrm{P}=0.66 \text { ). The mean reduction in the } \\
\text { size of hematoma after } 24 \text { hours in the labetalol and TNG groups was } \\
41.3 \pm 16 \text { cc and } 45 \pm 17.4 \text { cc, respectively ( } \mathrm{P}=0.95 \text { ). Hypotension was } \\
\text { observed in } 10 \% \text { of the labetalol group and in } 17.4 \% \text { of the TNG group } \\
\text { (P=0.01). Changes in mean systolic and diastolic blood pressure were not } \\
\text { significantly different between the two groups during } 24 \text { hours (P=0.83 and } \\
\mathrm{P}=0.99 \text {, respectively). } \\
\text { Conclusion: Both drugs are effective in reducing blood pressure and no } \\
\text { significant differences were observed between the two drugs in this regard. } \\
\text { Kevwords: Hypertension. Intracerebral Hemorrhage. Labetalol. Nitroglycerin }\end{array}$} \\
\hline $\begin{array}{l}\text { How to Cite this Article: } \\
\text { Mosalrezaei A, Valizade } \\
\text { Hasanloei MA, Kahoorian A. } \\
\text { Comparison of the Effects of } \\
\text { Trinitroglycerin Infusion and } \\
\text { Labetalol in the Management } \\
\text { of Acute Arterial Hypertension } \\
\text { in Intracerebral Hemorrhage } \\
\text { Patients Admitted to an } \\
\text { Intensive Care Unit. Avicenna J } \\
\text { Clin Med. 2018; 25(1): 12-19. } \\
\text { DOI: } 10.21859 / \text { ajcm.25.1.12. }\end{array}$ & \\
\hline & \\
\hline & \\
\hline
\end{tabular}


do): $10.21859 / \mathrm{ajcm} \cdot 25.1 .12$

\section{مقايسه انفوزيون نيتروكليسرين و لابتالول در كنترل برفشارى خون شريانى حاد بيماران دجار خونريزى داخل مغزى بسترى در بخش مر اقبتهاى ويزه

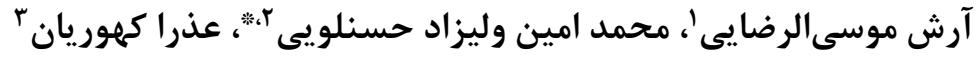

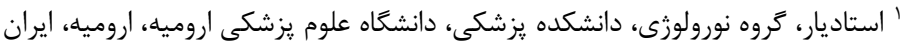

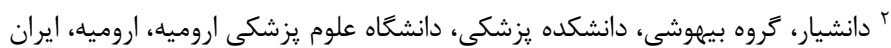

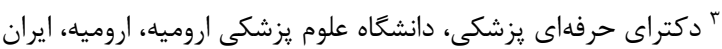

* نويسنده مسئول: محمد امين وليزاد حسنلويى، گروه بيهوشى، دانشكده يزشكى، دانشكاه علوم يزشكى اروميه، اروميه، ايران.

ايميل: aminvalizade@yahoo.com

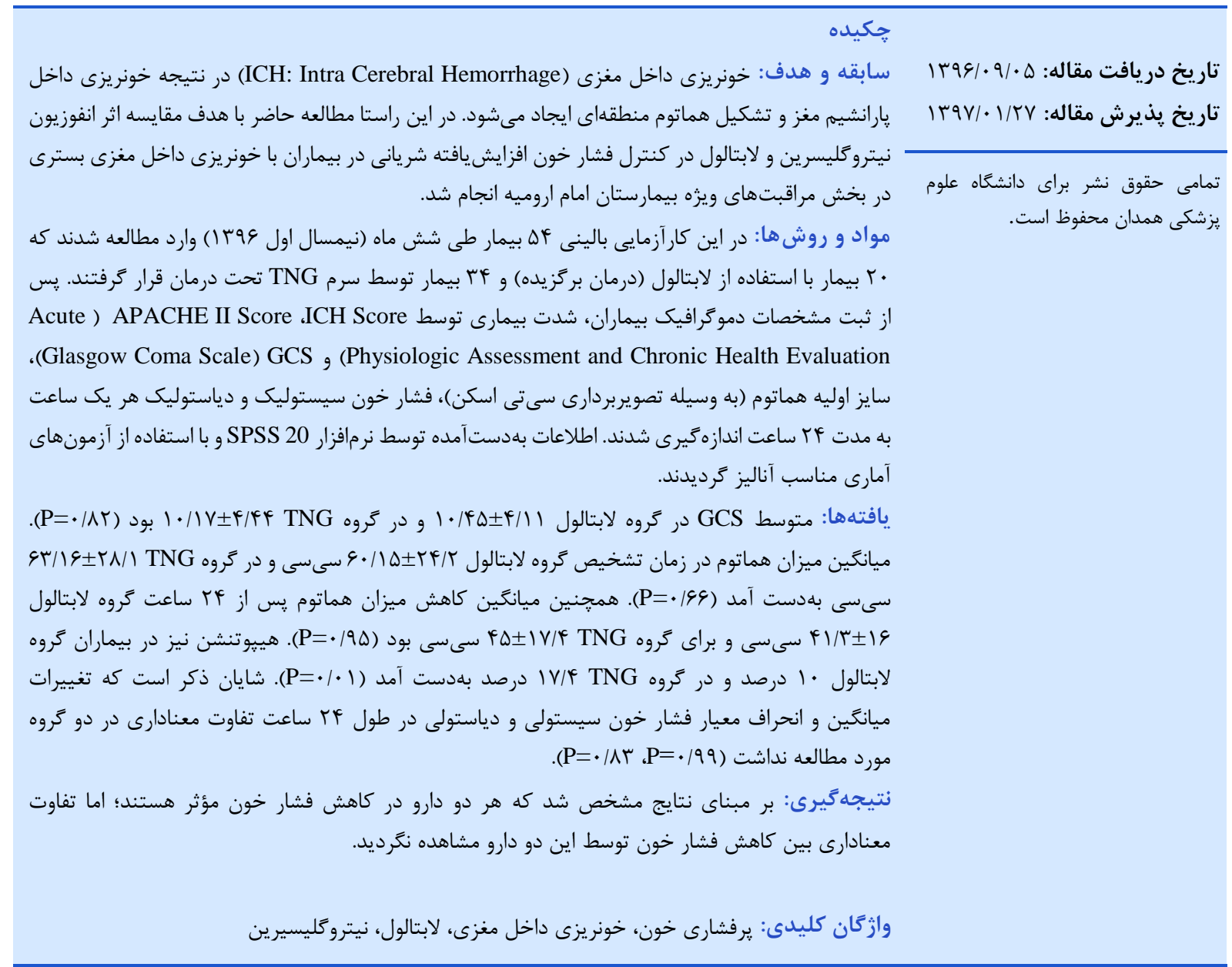

مقلdمه

ميرها در فاز حاد رخ مىدهند. ICH يك اورزانس يزشكى است كه تشخيص سريع و مديريت آن قاطعانه مىباشد كه مهد علت آن آن

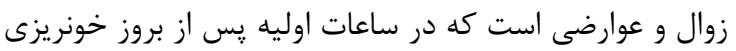

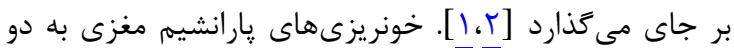

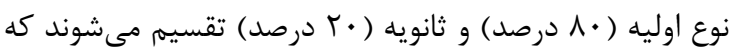

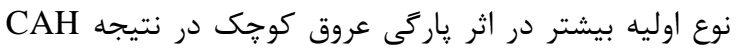

سكته مغزى در بين بيمارىهاى نورولوزيك در رتبه اول

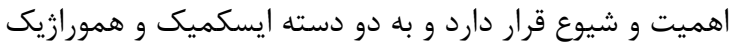

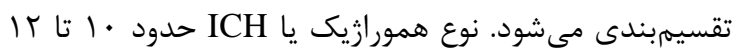

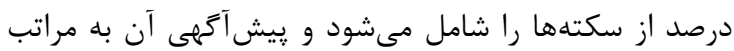

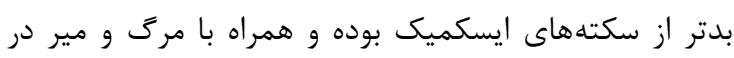

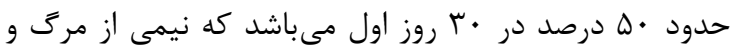


استفاده مىشود و نتايج اين طرح مطالعاتى مىتواند بهطور قابل

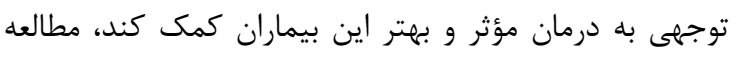

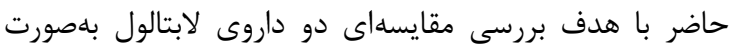

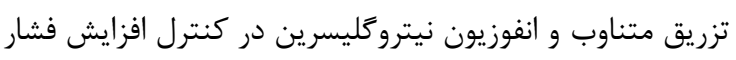

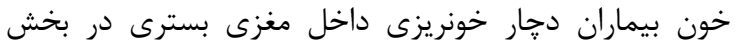

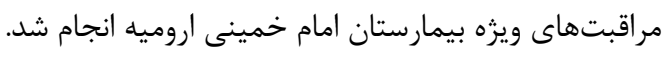

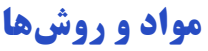

اين مطالعه كارآزمايى بالينى بِ إس از تصويب در كميته

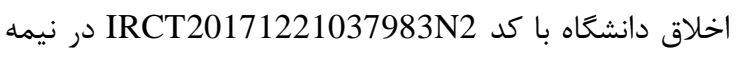

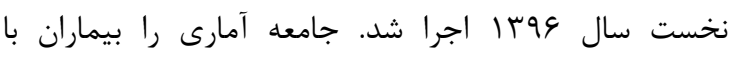

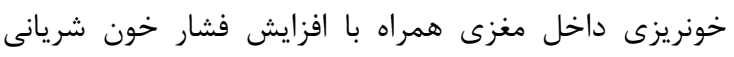

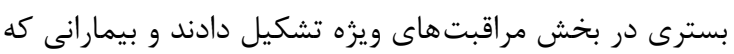

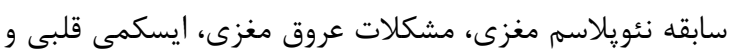

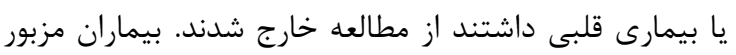

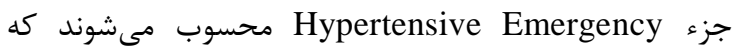
انديكاسيون كنترل سريع فشار خون بالا به وسيله داروهاى ضد

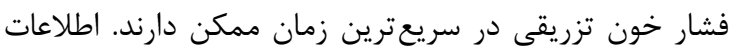

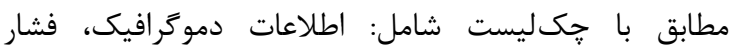
خون اوليه در زمان يذيرش بيمار، شدت بيمارى (توسط APACHE II Score ،ICH Score هماتوم (به وسيله تصويربردارى سىتى اسكن) جمعآورى مآن

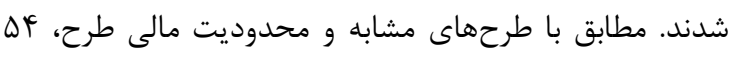
بيمار (با استفاده از نرمافزار

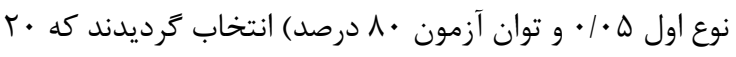

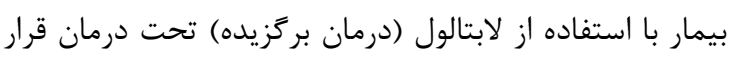

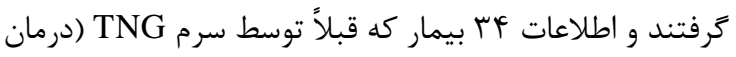

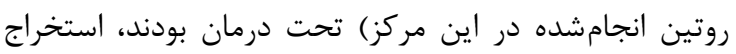

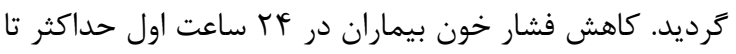

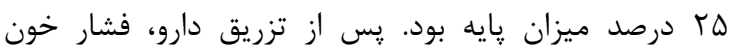

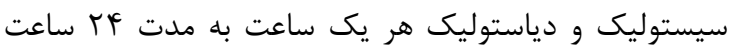

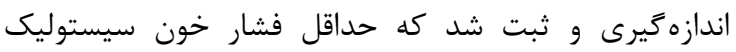

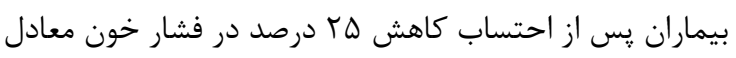

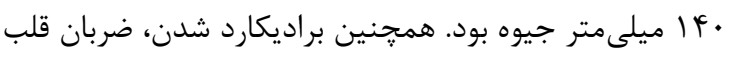

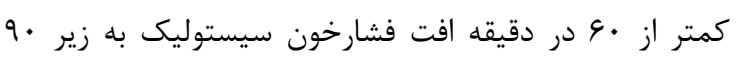

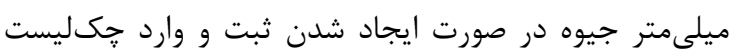

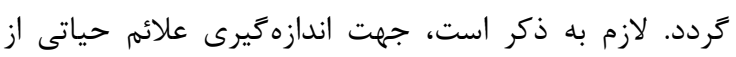

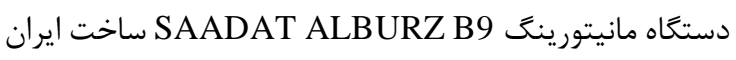
استفاده شد. ذكر اين نكته ضرورت دارد كه آميول لابتالول

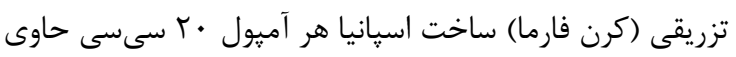

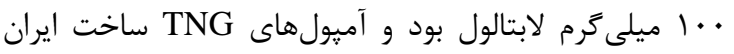

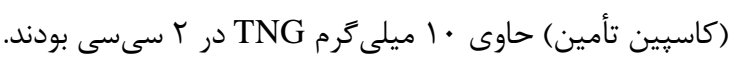

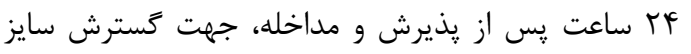

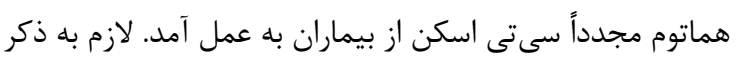

يا لييوهيالونيزهشدن و (Chronic Arterial Hypertention) با آميلوئيد آنزيوياتى ايجاد مىشود و نوع ثانويه در اثر تروما،

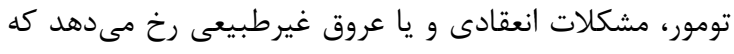

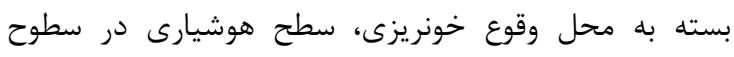

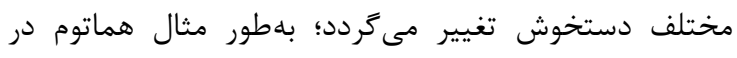

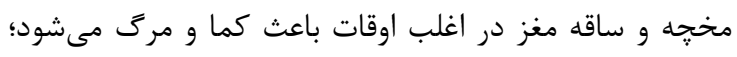

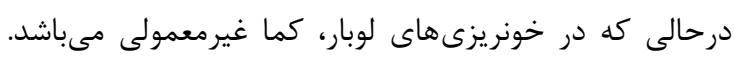

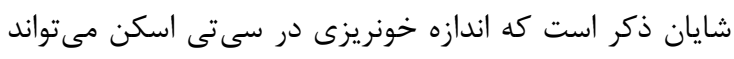

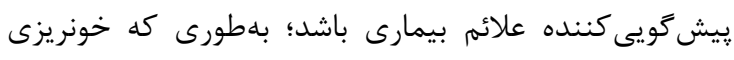

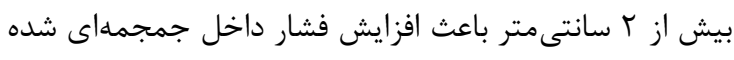

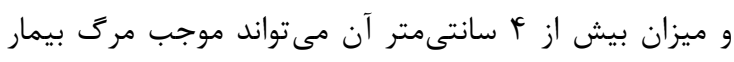

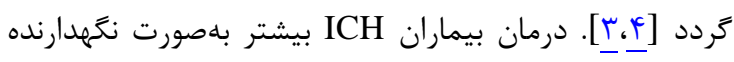

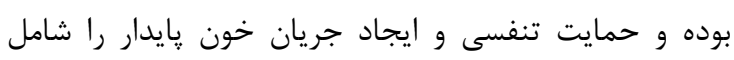

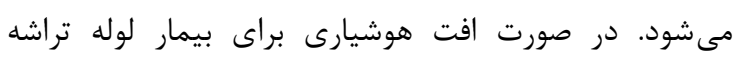
تعبيه مى تردد و كاهش

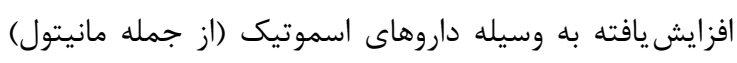

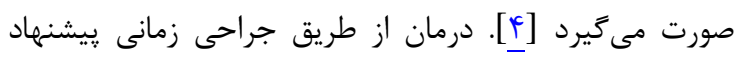

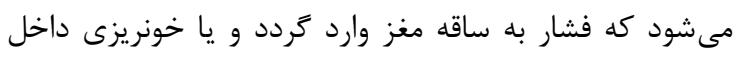

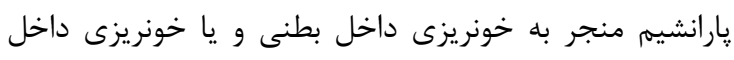

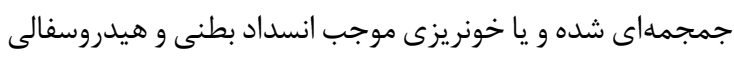

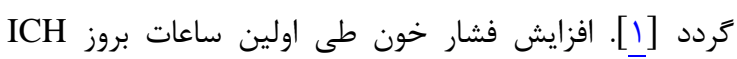

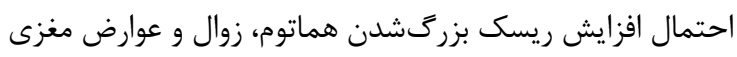

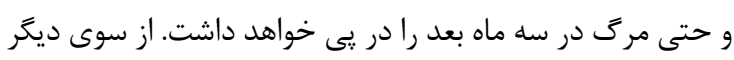

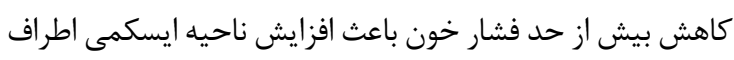

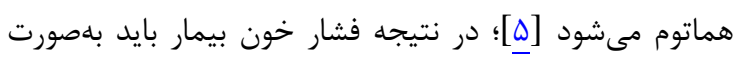

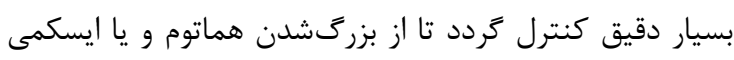

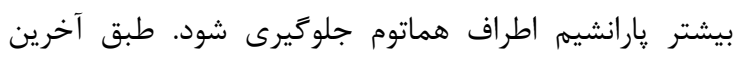

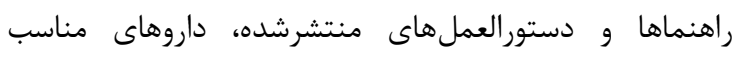

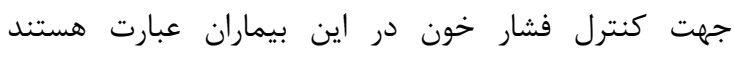

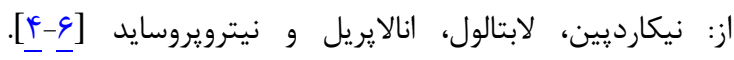

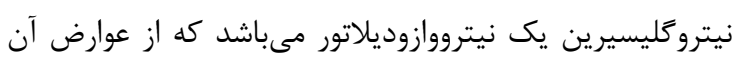

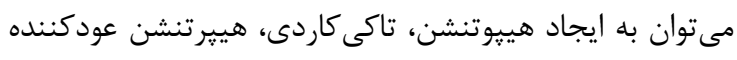
(Rebound Hypertention) اشاره كرد. بايد خاطرنشان ساخت كه در مقايسه با لابتالول،

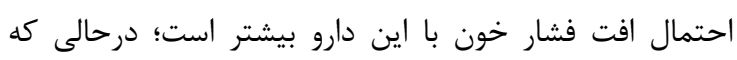

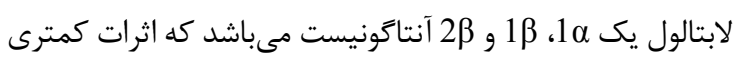

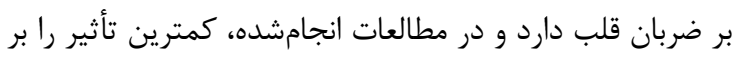

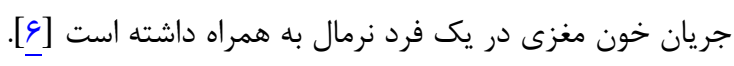

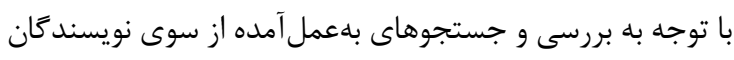

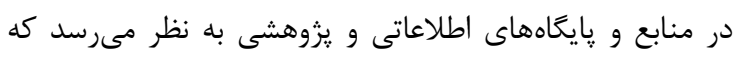

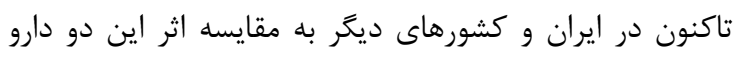

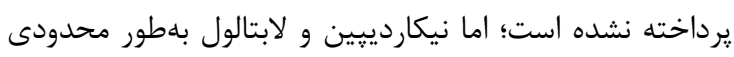

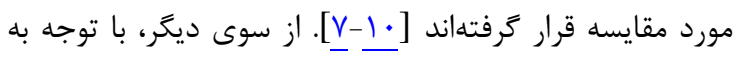

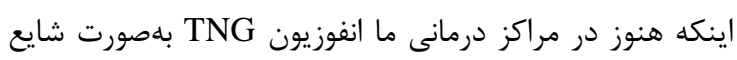


و دو نفر (9/9 درصد) در گروه TNG سيكارى بودند؛ اما هيج كدام

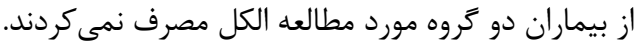

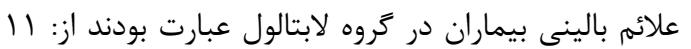

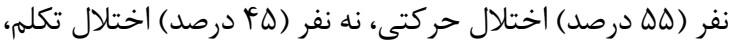

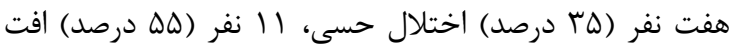
هوشيارى و سه نفر (لا درصد) افتادن ناگهانى.

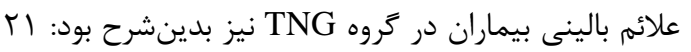

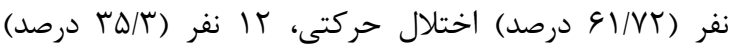

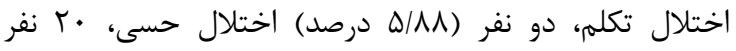

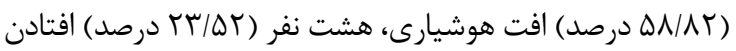
ناگمانى و يك نفر (r/9 درصد) تارى ديد.

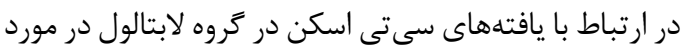

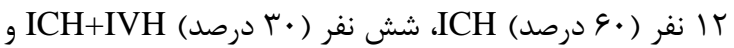
دو نفر ( • د درصد) ثبت شده بود و براى بيماران

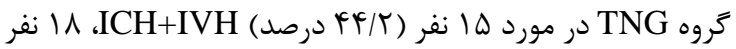

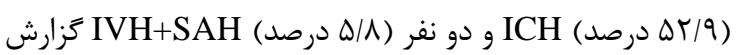

شده بود.

محل يافتههاى سىتى اسكن نيز بلهورت زير بود:

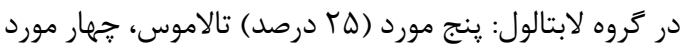

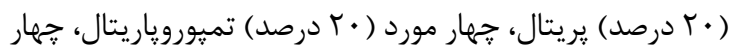

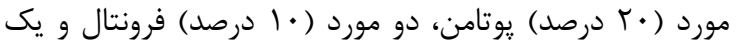
مورد (ل درصد) مخجه مورد

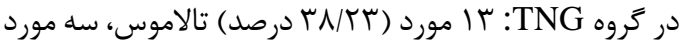

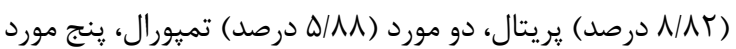

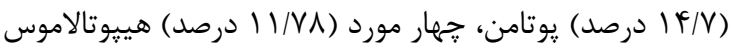
و شش مورد (V/GF

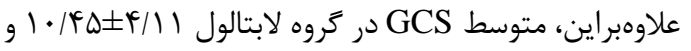

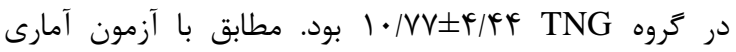

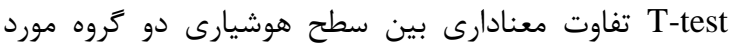

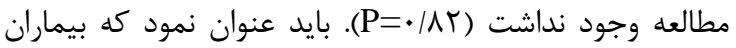
مورد مقايسه ترومايى نبودند.

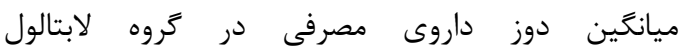

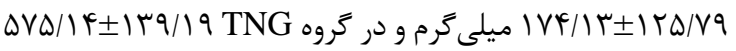

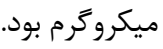
ميانكين ميزان هماتوم در زمان تشخيص در كرود  بود. مطابق با آزمون آمارى T-test تفاوت معنادارى بين هماتوم

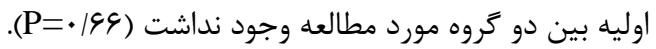

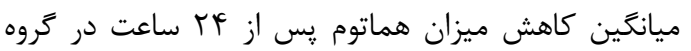

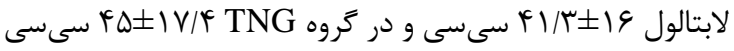

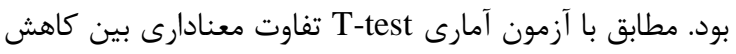

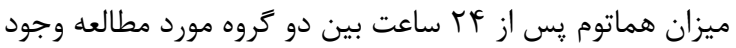

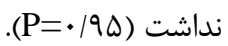
از سوى ديخر، ميانگين نمره APACHE II در كروه لابتالول

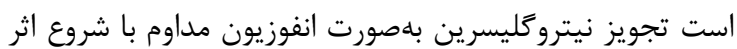

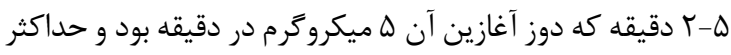

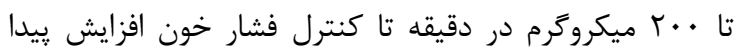

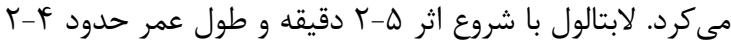

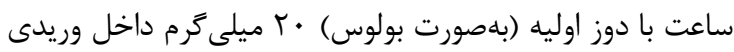

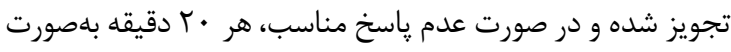

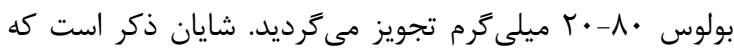

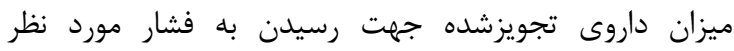

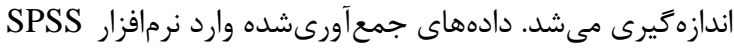

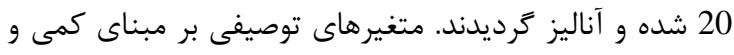
كيفىبودن بلهورت ميانگين با انحراف معيار و فراوانى ارائه شدند مبند

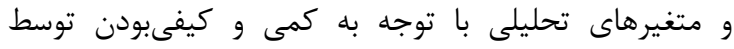

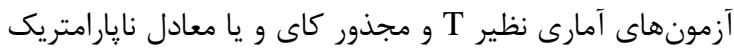
آنها مورد مقايسه قرار كرفتند. بايد خاطرنشان ساخت كاري كه

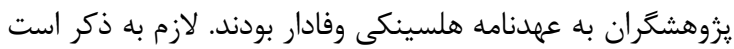

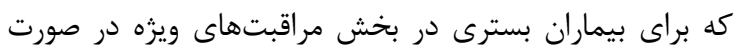

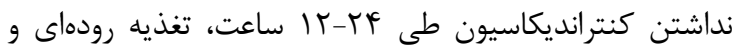

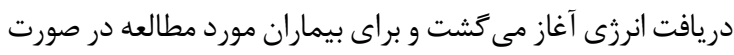

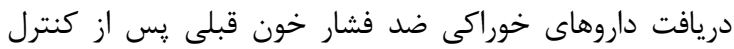

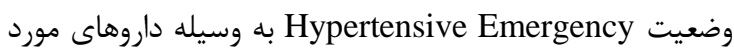
مطالعه تزريقى و شروع تغذيه انترال، داروهاى فوق ادامه پِيدا

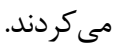

\section{يافته ها}

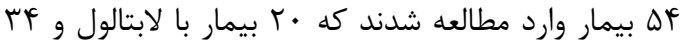
بيمار با انفوزيون سرم TNG تحت درمان قرار گرفتند.

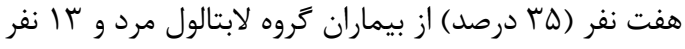

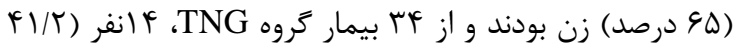

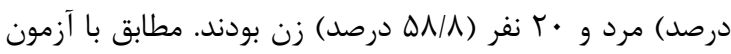

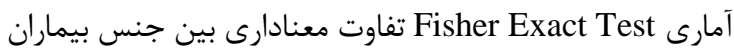

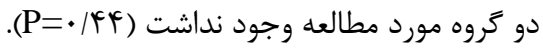

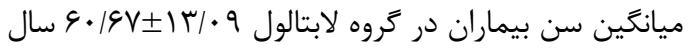

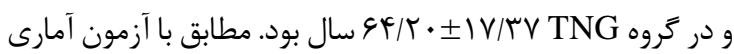
T-test

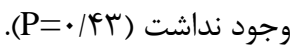

در گروه لابتالول تنها سه نفر (لا الدرصد) سابقه بيمارى فشار

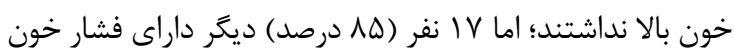

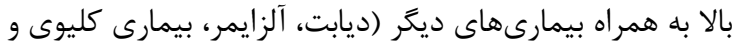
تيروئيد) و يا تنها فشار خون باه بالا بودند. بوند

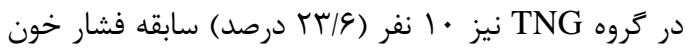

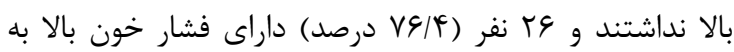
همراه بيمارى هاى ديگر (ديابت و بيمارى كليوى) و يا تنها فشار

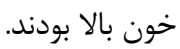
لازم به ذكر است كه جهار نفر (•r درصد) در گروه لابتالول 


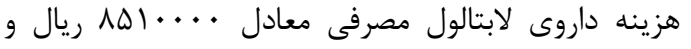

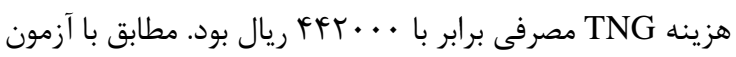

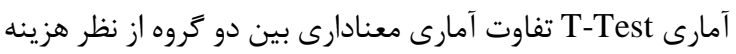

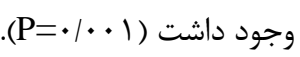
در اين مطالعه در هر دو گروه ميانكين و انحراف معيار فشار

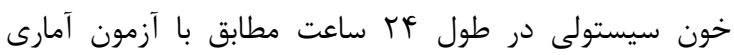

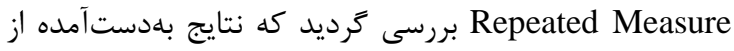

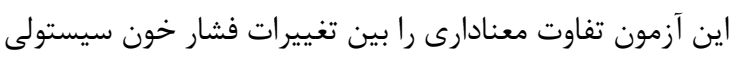

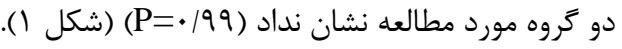

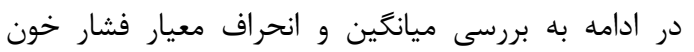

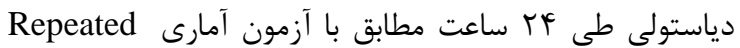

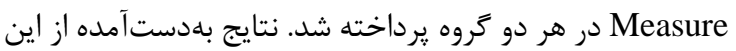

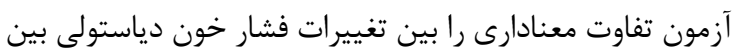

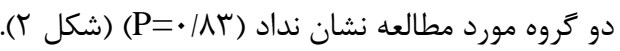

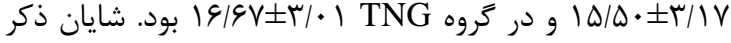
است كه تفاوت معنادارى از نظر نمره APACHE II بين دو دو كروه مورد مطالعه وجود نداشت (P=•/1) (جدول (1).

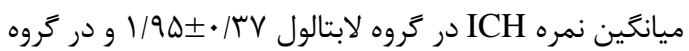
و 9 TNG

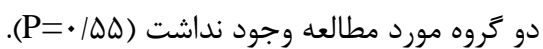

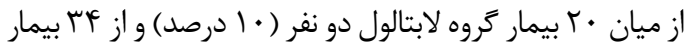

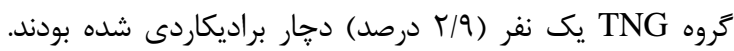

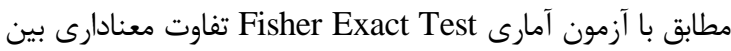

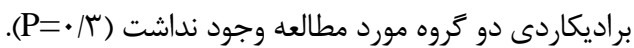

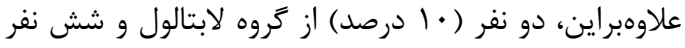

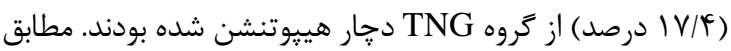

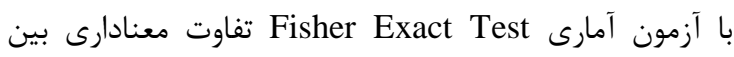

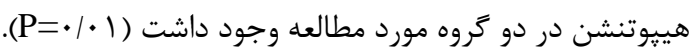

\begin{tabular}{|c|c|c|c|}
\hline معنادارى & Tروه TNG & كروه لابتالول & \\
\hline$\cdot \operatorname{lAt}$ & $1 \cdot / l V \pm F / F F$ & $1 \cdot / f \Delta \pm F / 11$ & GCS \\
\hline$\cdot / 1 \Lambda$ & $|\varepsilon| \& \vee \pm r / \cdot 1$ & $|Q / \omega \cdot \pm r /| V$ & APACHE II \\
\hline$\cdot 199$ & $\varepsilon r / \backslash 9 \pm \Gamma \wedge / 1$ & $G \cdot / 1 \Delta \pm T F / T$ & ميزان هماتوم در زمان تشخيص \\
\hline$\cdot 190$ & $\varphi \Delta \pm \mid V / F$ & $f \mid / r \pm 19$ & كاهش ميزان هماتوم يس از TF ساعت \\
\hline
\end{tabular}

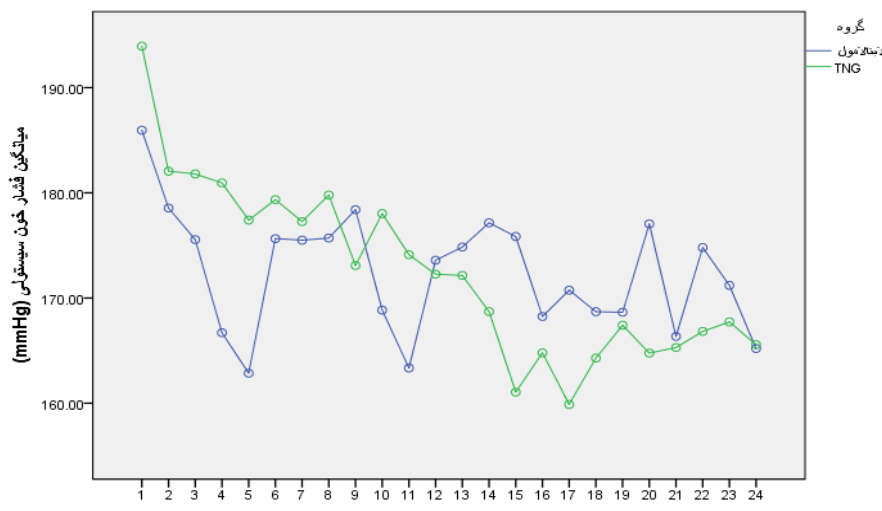

زمان

شكل ا: ميانحين و انحراف معيار فشار خون سيستولى طى TF ساعت در دو گروه مورد مطالعه

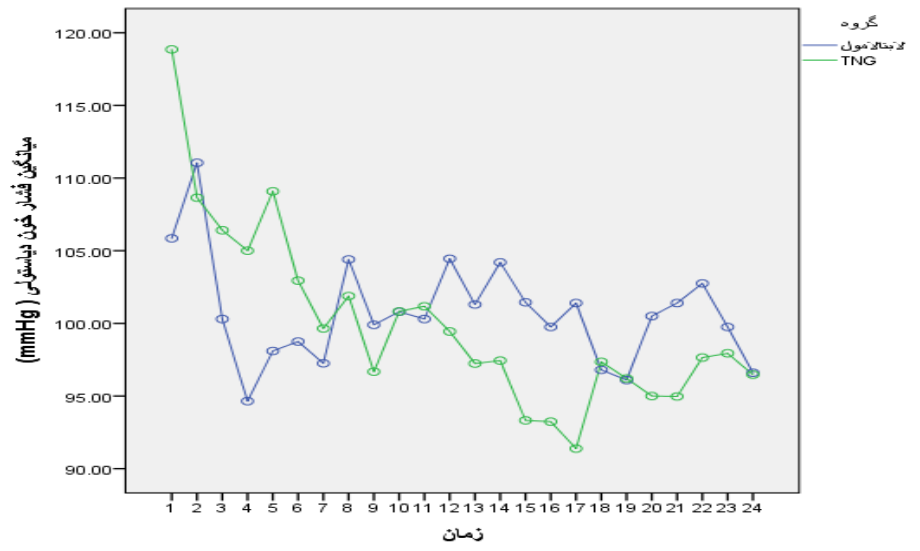

شكل r: ميانگين و انحراف معيار فشار خون دياستولى طى بF ساعت در دو گروه مورد مطالعه 
كرفته شد [ץ]. مطالعه حاضر از نظر كنترل ميزان هماتوم با

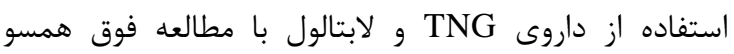

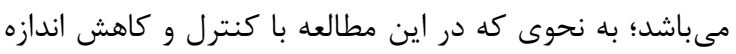

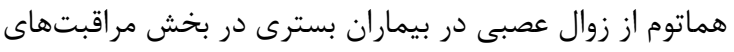

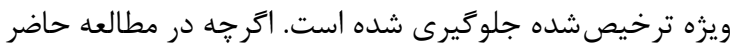

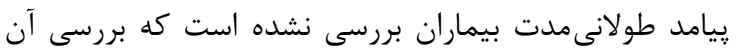

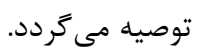
علاوهبراين، يافتههاى مطالعه حاضر نشان داد كه تفاوت

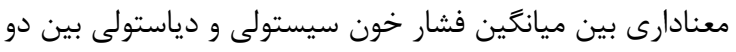

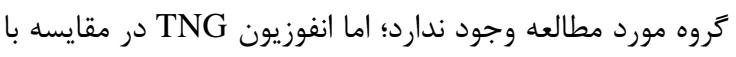

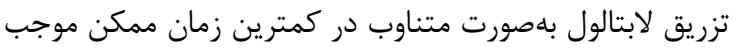

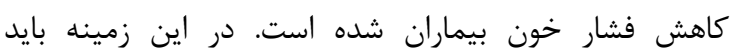

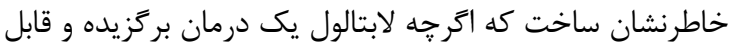

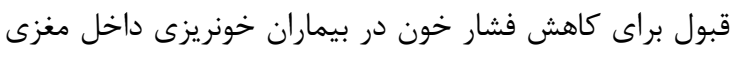

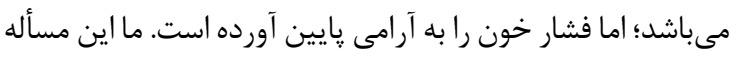

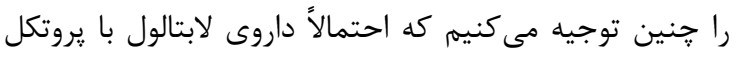

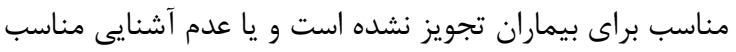

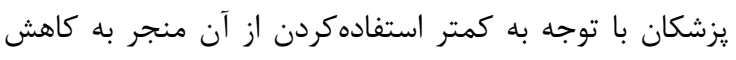

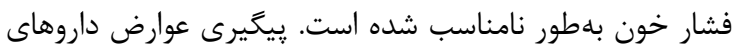

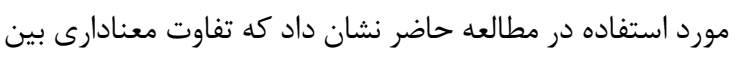

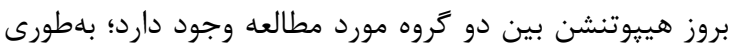

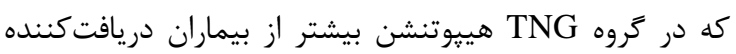

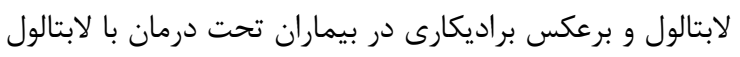

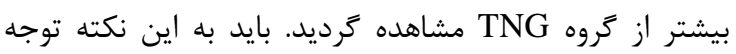

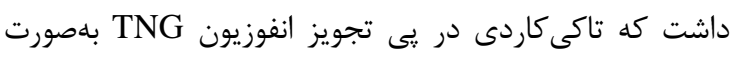

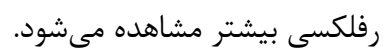

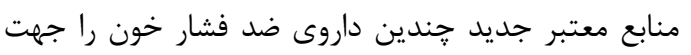

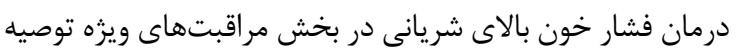

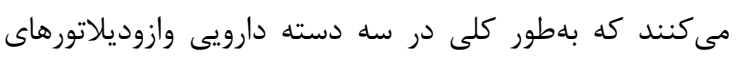

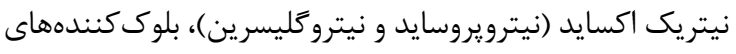
كانال كلسيمى (كلويديبين و نيكارديبين) و و متفرقه شاملين

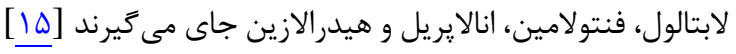

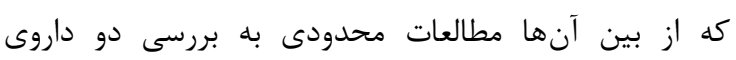

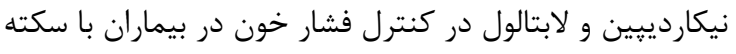

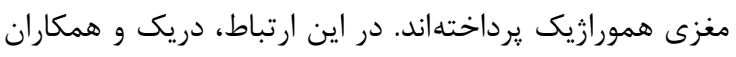

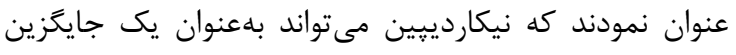

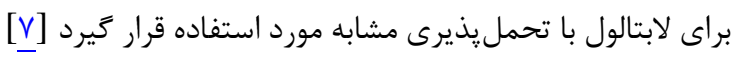

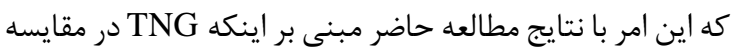

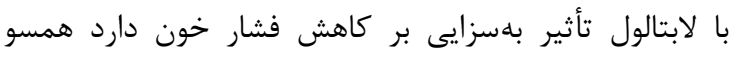

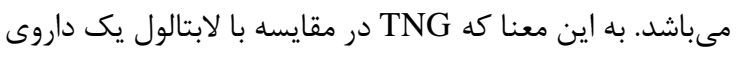

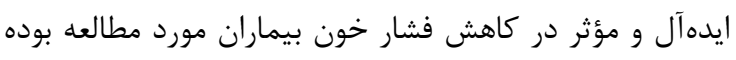

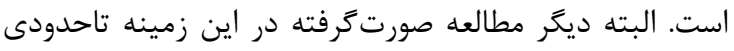

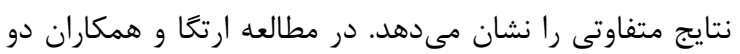

سكته مغزى شايعترين بيمارى مغز و اعصاب در بزر كسالان است. خونريزى اوليه مغز كه به دليل فشار خون بالار رخ مي دهند،

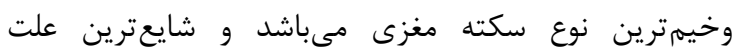

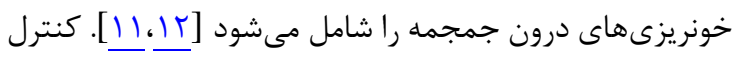

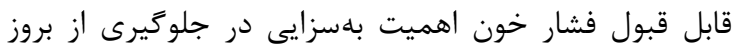

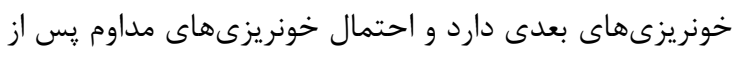

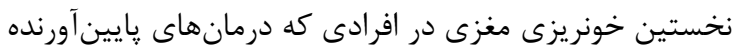

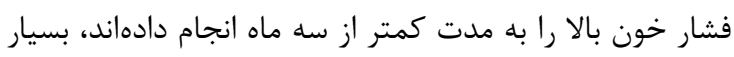

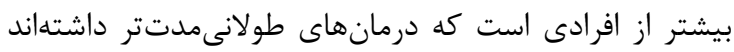

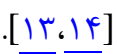

در مطالعه حاضر به مقايسه اثر تزريق لابتالول بهصورت

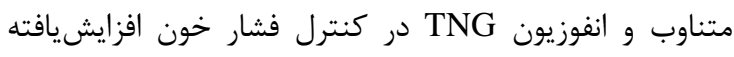

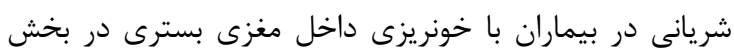

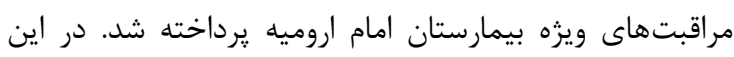

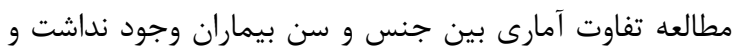

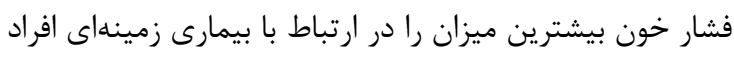

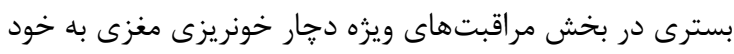

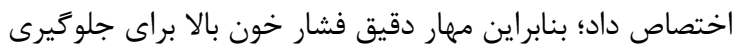
از خونريزى مغزى بسيار مهم مى دياشد.

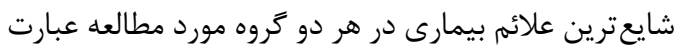

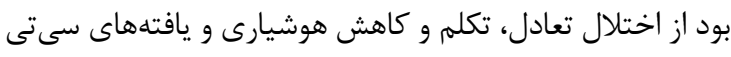

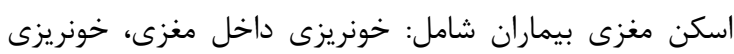

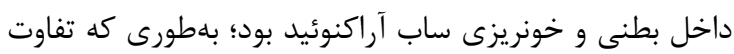

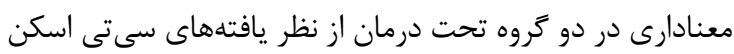

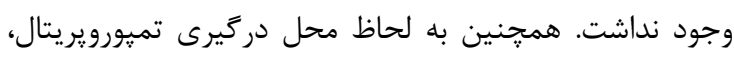
مخجه و فرونتال، تالاموس بيشترين محل در ديرى دها بود.

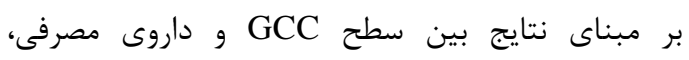

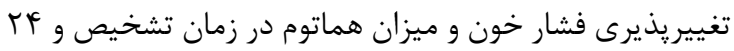

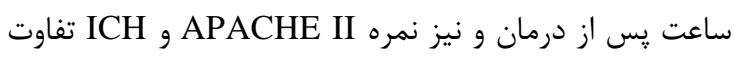

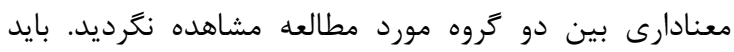

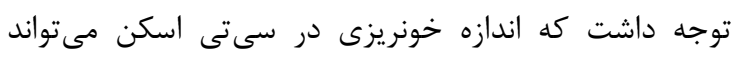

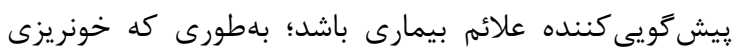

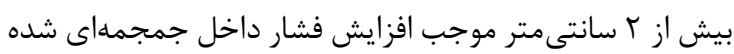

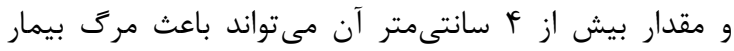

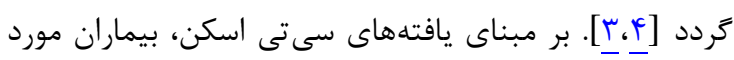

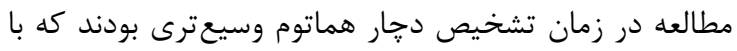

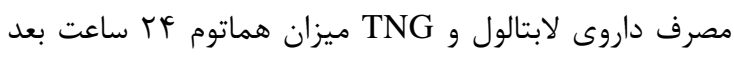

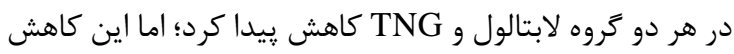

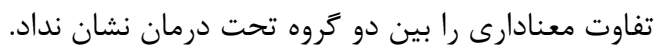

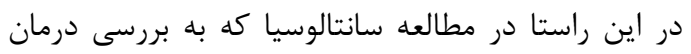

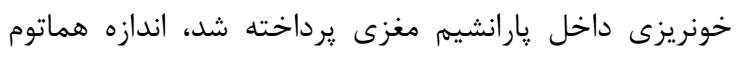

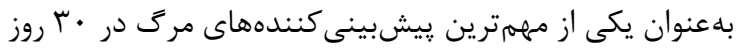

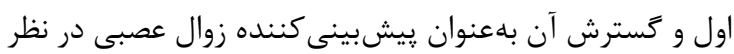


روتين براى بيماران استفاده نمىشد، مجرى طرح مىبايست خود

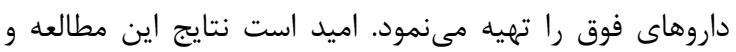
سياستهاى درمانى باعث رفع اين محدوديتها بشوند.

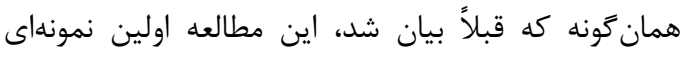

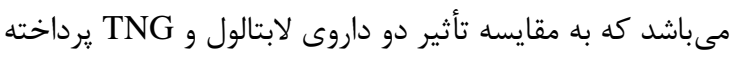

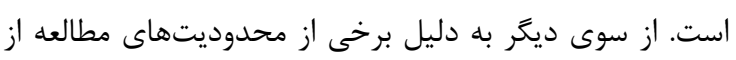
جمله عوامل مخدوش

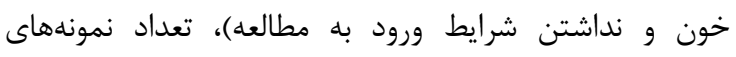
انتخابشده در مقايسه با مطالعات بررسى شده در اين زمينه كمتر

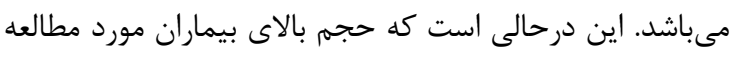

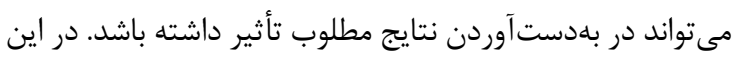

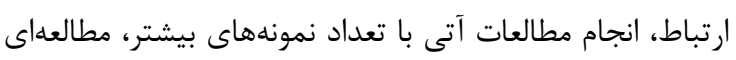

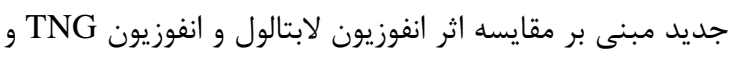

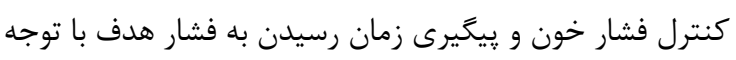
به نوع خونريزى و شدت آن توصيه مى گردد.

\section{نتيجه تيرى}

يافتههاى مطالعه حاضر نشان داد كه انفوزيون TNG و تزريق

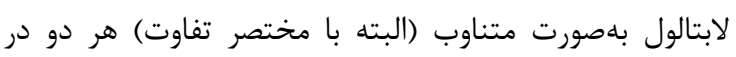

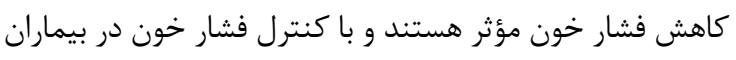

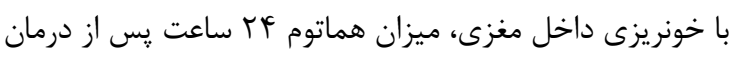

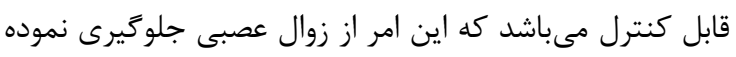

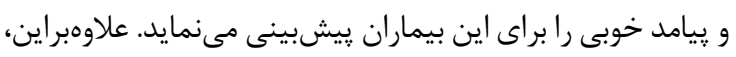

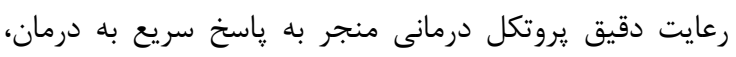
كاهش ميزان دوز مصرفى و كاهش ميزان هماتوم خواهد كرديد.

\section{تشكر و قلر داذى}

بدينوسيله از معاونت يروهشى دانشكاه علوم يزشكى اروميه،

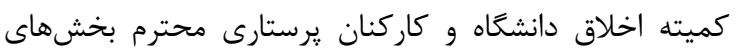

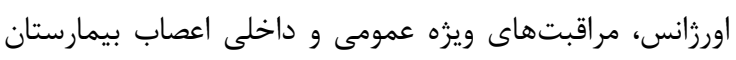

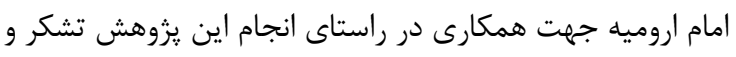

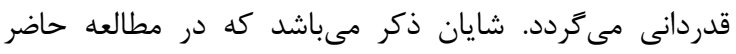

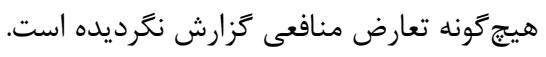

\section{REFERENCES}

1. Hemphill JC 3rd, Greenberg SM, Anderson CS, Becker K, Bendok BR, Cushman M, et al. Guidelines for the management of spontaneous intracerebral hemorrhage a guideline for healthcare professionals from the American heart association/American stroke association. Stroke. 2015;46(7):2032-60.PMID: 26022637DOI: 10.1161/STR. $\underline{0000000000000069}$

2. Ropper AH, Samuels MA, Klein JP. Craniocerebral trauma. In: Ropper AH, editor. Adams and Victor`s principle of neurology. $10^{\text {th }}$ ed. New York:McGraw-Hill; 2005.

3. Santalucia P. Intracerebral hemorrhage: medical treatment. Neurol Sci. 2008;29(2):S271-3. PMID: 18690516DOI: 10.1007/s10072-008-0961-y

4. Sacco S, Marini C, Carolei A. Medical treatment of intracerebral hemorrhage. Neurol Sci. 2004;25(Suppl 1):S6-
داروى نيكاردييين و لابتالول به يك اندازه براى كنترل فشار

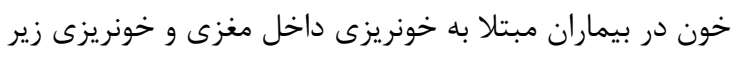

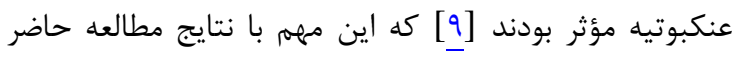

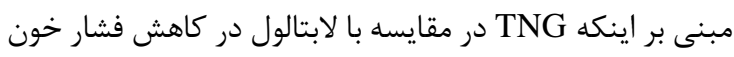

$$
\text { مؤثر بوده است مغايرت دارد. }
$$

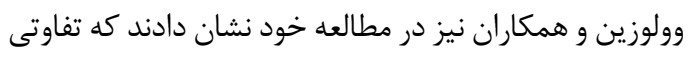

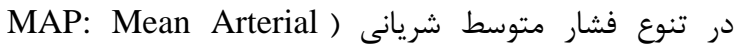
(Pressure نيكاردييين موجب پاسخ سريع به درمان و شكست درمان كمتر

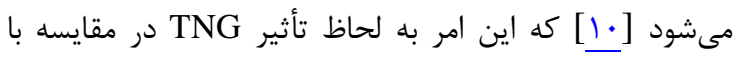
لابتالول با نتايج مطالعه حاضر همسو مئ بـاشد.

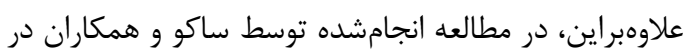

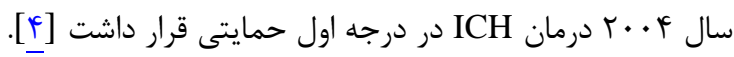

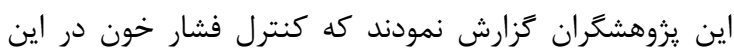

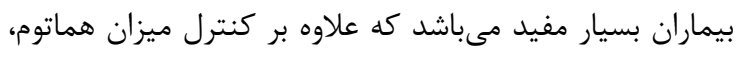

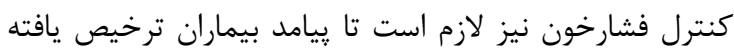

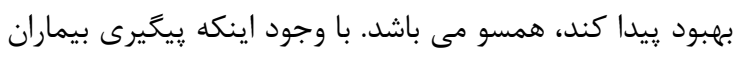

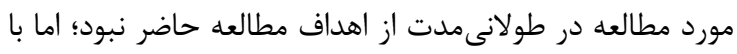
اين حال مى توان جنين برآورد كرد كه با كنترل ميزان هماتوم و مولاني

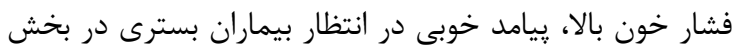
مراقبتهاى ويزه خواهد بود. لازم به ذكر مىباشد كه در اين مطالعه به دليه دود بليل متغيربودن

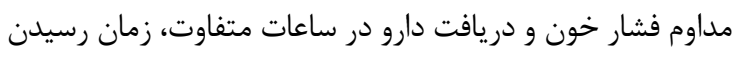

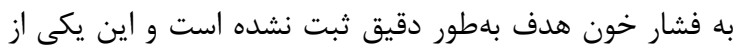

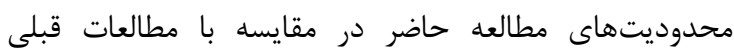

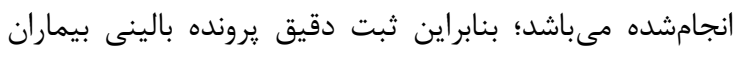

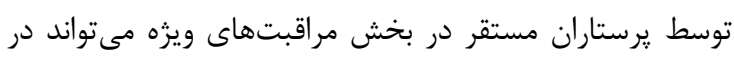

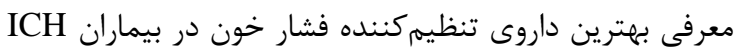

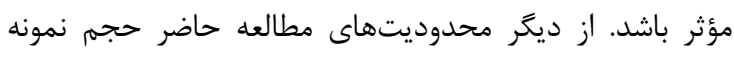

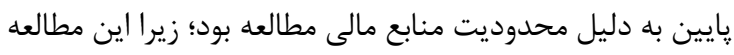

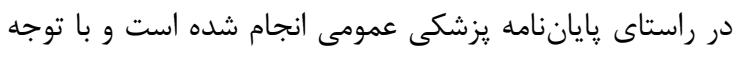

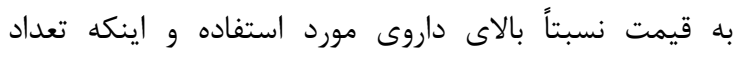
آميولهاى مورد نظر بالاتر از كمك دريمت ديافتى از سوى دوى معاونت

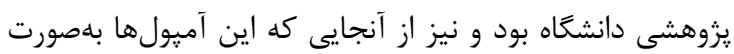

9. PMID: 15045610DOI: 10.1007/s10072-004-0206-7

5. Zazulia AR, Diringer MN, Videen TO, Adams RE, Yundt K, Aiyagari V, et al. Hypoperfusion without ischemia surrounding acute intracerebral hemorrhage. J Cereb Blood Flow Metab. 2001;21(7):804-10.PMID: 11435792DOI: 10.1097/00004647-200107000-00005

6. Yazbeck MF, Rincon F, Mayer SA. Interacerebralhemorrhage. The neuro ICU book.New York:McGraw Hill; 2012. P. 35-51.

7. Liu-Deryke X, Janisse J, Coplin WM, Parker D Jr. Norris G Rhoney DH. A comparison of nicardipine and labetalol for acute hypertension management following stroke. Neurocrit Care. 2008;9(2):167-76.PMID: 18250979DOI: $10.1007 /$ s12028-008-9057-Z

8. Anderson CS, Heeley E, Huang Y, Wang J, Stapf C,Delcourt 
$\mathrm{C}$, et al. Rapid blood-pressure lowering in patients with acute intracerebral hemorrhage. N Engl J Med. 2013;368(25):235565.PMID: 23713578DOI: 10.1056/NEJMoa1214609

9. Ortega-Gutierrez S, Thomas J, Reccius A, Agarwal S, Lantigua $\mathrm{H}$, Li M, et al. Effectiveness and safety of nicardipine and labetalol infusion for blood pressure management in patients with intracerebral and subarachnoid hemorrhage. Neurocrit Care. 2013;18(1):13-9.PMID: 23055089DOI: 10.1007/s12028-012-9782-1

10. Woloszyn AV, McAllen KJ, Figueroa BE,DeShane RS, Barletta JF. Retrospective evaluation of nicardipine versus labetalol for blood pressure control in aneurysmal subarachnoid hemorrhage. Neurocrit Care. 2012;16(3):37680.PMID: 22528277DOI: 10.1007/s12028-012-9700-6

11. Victor M, Ropper AH. Cerebrovascular disease. In: Victor M, Ropper AH, editors. Adams and Victor's principles of neurology. $7^{\text {th }}$ ed. New York: McGraw-Hill; 2001. P. 821924
12. Iniesta JA,Corral J, González-Conejero R, Piqueras C, Vicente V.Polymorphisms of platelet adhesive receptors: do they play a role in primary ICH. Cerebrovasc Dis. 2003;15(12):51-5.PMID: 12499711DOI: 10.1159/000067126

13. Jørgensen HS, Nakayama H, Christensen HR, Raaschou HO, Kampmann JP, Olsen TS.Blood pressure in acute stroke. The Copenhagen Stroke Study. Cerebrovascular Dis. 2002;13(3):204-9. PMID: 11914539DOI: 10.1159/ 000047777

14. Bae HG, Jeong DS, Doh JW, Lee KS, Yun IG, Byun BJ. Recurrence of bleeding in patients with hypertensive ICH. Cerebrovascular Dis. 1999;9(2):102-8. DOI: 10.1159/ $\underline{000015906}$

15. Donahoe M. Very high systemic arterial blood pressure. In: Vincent JL, Abraham E, Moore FA, Kochanek PM, Fink MP, editors. Text book of critical care. $7^{\text {th }}$ ed. New York: Elsevier; 2017. P. 19-23. 